\title{
Kinetics and mechanism of the oxidation of some cis-Alpha- Phenylcinnamic acids by Pyridinium Chlorochromate
}

\author{
S. Nalini ${ }^{1}$, R. Udhayakumar ${ }^{*}$, K.Anbarasu $^{3}$, P.Manivannan $^{4}$, K.Raghu $^{5}$ \\ ${ }^{1}$ Department of Chemistry, Periyar Arts College, Cuddalore -607001 \\ Email: nalinikumaran73@gmail.com \\ $2^{*}$ Department of Chemistry, Bharathidasan Institute of Technology (BIT) Campus, Anna University, \\ Tiruchirappalli-620024, Tamilnadu, India. \\ Email: udhaya0123@gmail.com \\ ${ }^{3}$ Department of Chemistry, Arignar Anna Govt. Arts College, Musiri - 621211 \\ Email:arasu007@gmail.com \\ ${ }^{4}$ Department of Chemistry, IFET College of Engineering, Villupuram - 605108 \\ Email:mani098@gmail.com \\ ${ }^{5}$ Department of Chemistry, Krishnasamy College of Engineering \& Technology, Cuddalore -607109 \\ Email:ragukpatham@gmail.com
}

\begin{abstract}
Oxidation of cis $\alpha$-phenyl cinnamic acids by pyridinium chlorochromate (PCC) was studied in acetic acid-water mixture containing perchloric acid. The reaction rate is first order in $[\mathrm{PCC}]$ and fractional order in $\left[\mathrm{H}^{+}\right]$and has aldehyde as a product. The rate of reaction increases with increase in the percentage of acetic acid medium. The reactions exhibit kinetic isotope effect. The activation parameters have been evaluated. The added Mn (II) decreases the rate of reaction. The added sodium chlorate has no effect on the reaction rate and indicates the absence of ion-ion (or) ion- dipole interaction in the slow step. The deviation of Hammett plot is noted and a "V" shaped curve is obtained.
\end{abstract}

Keywords. Kinetics; oxidation; cis- $\alpha$-Phenyl cinnamic acids; Pyridinium Chorochromate.

\section{INTRODUCTION}

Chromium compounds have been widely used in aqueous and non-aqueous media for the oxidation of a variety of organic compounds. Chromium (VI) reagents especially have been proved to be versatile reagents capable of oxidizing almost all oxidizable organic functional groups ${ }^{1}$. Depending on the substrate and experimental conditions $\mathrm{Cr}(\mathrm{VI})$ functions both as a one and a two-electron oxidant ${ }^{2-6}$. Kinetics of oxidation of some organic substrate by PCC has already been reported $^{7-20}$. In this paper, the oxidation of cis- $\alpha$-phenyl cinnamic acids by pyridinium chlorochromate in aqueous acetic acid medium is reported.

\section{EXPERIMENTAL}

\subsection{Materials}

Pyridinium chlorochromate (PCC) was prepared by the method of Corey and Sugg ${ }^{16}$. Cis- $\alpha$-phenyl cinnamic acid was prepared by $42.5 \mathrm{~g}$ of purified benzaldehyde, $54.4 \mathrm{~g}$ of phenyl acetic acid, $80 \mathrm{ml}$ of redistilled acetic anhydride and $40 \mathrm{ml}$ of anhydrous triethylamine was placed in a $500 \mathrm{ml}$ round bottomed flask fitted with a reflux condenser and drying tube. The mixture was boiled gently for 5 hours. The mixture was steam distilled directly from the reaction flask until the distillate passing over was no longer cloudy, and $50 \mathrm{ml}$ of distillate was further collected and discarded. The yield of a-phenyl cinnamic acid is $55 \mathrm{~g}\left(\mathrm{~m} . \mathrm{p} .172-173^{\circ} \mathrm{C}\right)^{21}$.

\subsection{Product Analysis}

The reaction mixture was kept for $48 \mathrm{hrs}$. to ensure completion of the reaction. After completion of the reaction, the reaction mixture was extracted with chloroform. The Solvent was removed by distillation at reduced pressure. Spotting on the TLC plates (silica gel with binder) showed two spots which were made visible by exposure to iodine. They exactly corresponded to $R_{f}$ value of the authentic samples of benzaldehyde and unreacted cis- $\alpha$-phenyl cinnamic acid. Another expected product was phenyl glyoxalic acid but in strong acid medium it may undergo further decomposition to give benzaldehyde. The products of cis- a-phenyl cinnamic acid oxidation were confirmed as their 2,4 -DNP derivatives.

\subsection{Stoichiometry}

The reaction mixture containing excess of oxidant (PCC) in the presence of perchloric acid was kept for $24 \mathrm{hrs}$. Under kinetic conditions, the estimation of unreacted oxidant indicated that two moles of oxidant were used up by one mole of cis- $\alpha$-phenyl cinnamic acid.

\subsection{Kinetic Measurements}

All the kinetic runs of cis- $\alpha$-phenylcinnamic acid with PCC were performed under isolated conditions, i.e.,[cis- $\alpha$ phenylcinnamic acid] >> [oxidant] in acetic acid-water $(1: 1 \mathrm{v} / \mathrm{v})$ solvent mixture. The rate of the reaction was followed iodometrically. All measurements were made at 303,308,313, and $318 \mathrm{~K}$. Required concentration of substrate solution were prepared in pure acetic acid and perchloric acid were prepared in double distilled water. Solutions of known volumes 
of perchloric acid and cis- a-phenyl cinnamic acid were mixed in a reaction flask. Calculated amount of acetic acid was added into the flask to bring the required proportion of the solvent-mixture in the reaction medium.

All the solutions were thermostated for 30 minutes. Then the reaction was started by adding a known volume of PCC, $2 \mathrm{ml}$ aliquot was withdrawn from the reaction mixture and quenched in excess of acidified potassium iodide was titrated against standard sodium thiosulphate solution using starch as an indicator. The pseudo-first order rate constant, for each kinetic run was evaluated from the slopes of linear plots of log titre versus time. The slopes were calculated by the method of least squares.

\section{RESULTS AND DISCUSSION}

\subsection{Effect of Variation of [Substrate]}

At constant [PCC], the increase in [substrate] enhances the reaction rate. The plot of log $k_{\text {obs }}$ versus [substrate] for different initial concentration of substrate is linear with slope equal to 0.86 indicating the fractional order dependence on substrate (Fig.1) (Table 1).

\subsection{Effect of Variation of [PCC]}

At constant [substrate], the increase in [PCC], the plot of log $\mathrm{k}_{\mathrm{obs}}$ versus time is found to be linear, indicating a first order dependence on [PCC]. The pseudo first order rate constant $k_{o b s}$, calculated from the slope of the above plot is found to be independent of the initial concentration of PCC (Table 1).

\subsection{Effect of Variation of $\left[\mathrm{H}^{+}\right]$}

The concentration of $\left[\mathrm{HClO}_{4}\right]$ is varied from 0.1 to $0.4 \mathrm{M}$ at fixed concentration of other reaction ingredients. The rate of reaction increases with increase in $\left[\mathrm{HClO}_{4}\right]$ (Table 1). The plot of log $\mathrm{k}_{\text {obs }}$ versus log $\left[\mathrm{H}^{+}\right]$gave a straight line $(\mathrm{r}=0.999)$ with slope equal to 0.54 . The order with respect to the acid is fractional (Fig.2). This may be due to the protonation of PCC in the above range of acid concentration ${ }^{20}$.

\subsection{Effect of lonic Strength}

The rate of reaction decreases with increase in concentration of added $\mathrm{MnSO}_{4}$. This may be due to the formation of $\mathrm{Cr}$ (IV) in the rate determining step. There is no appreciable change in $\mathrm{k}_{\text {obs }}$ value when the ionic strength is increased by sodium perchlorate. It indicates the absence of ion-ion (or) ion-dipole interaction in the slow step (Table.2).

\subsection{Effect of Solvent Composition}

At fixed ionic strength and $\left[\mathrm{H}^{+}\right]$, the rate of oxidation of cis a-phenyl cinnamic acids by pyridinium chlorochromate (PCC) increases with increase the percentage of acetic acid. This may be due to the increase in the acidity of the medium.

\subsection{Effect of Temperature}

The oxidation of the cis a-phenyl cinnamic acids were carried out at different temperature between the range of 303 to 318 $\mathrm{K}$ at constant concentrations of substrate and the oxidant. The rate constants are given in Table 3 . The plots of log $k_{\mathrm{obs}}$ versus $1 / T$ are linear (Fig.3). Activation parameters are presented in Table 3 . The negative values of entropy of activation reflect that the transition state is more rigid than initial state.

\subsection{Mechanism}

In aqueous solution PCC undergoes protonation ${ }^{20,22}$ at moderate acid concentration. The protonated species is more reactive than unprotonated species. Such protonation is not possible for cis- $\alpha$-phenyl cinnamic acids at these acidities. Study on the effect of added $\mathrm{Mn}$ (II) suggest that the rate controlling process produces tetravalent chromium, involving a two electron change.

Based on the above observation, a probable mechanism is suggested, which is given below. 
<smiles>[O-][C+]([OH2+])[O+][PH3+]</smiles><smiles>O=C(O)/C=C\c1ccccc1</smiles><smiles></smiles><smiles>O=C(O)C1(c2ccccc2)OC([TeH])(c2ccccc2)C1(O)Cl</smiles>

(C) $\underset{\mathrm{k}_{3}}{\stackrel{\text { Slow }}{\longrightarrow}}$

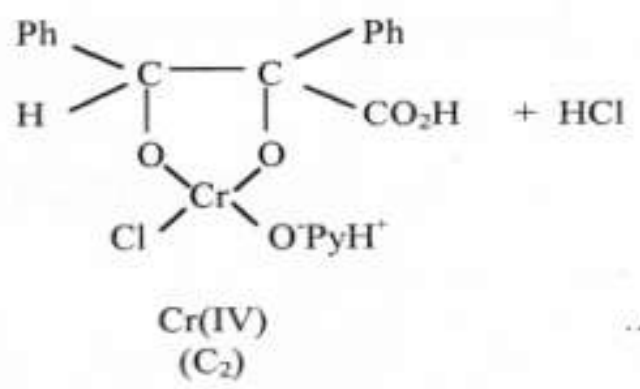

\subsection{Structural Effects}

The entropy of activation and heat of reaction are correlated by the equation

$$
\Delta H^{\#}=\Delta H_{0}^{\#}+\beta \Delta S^{\#},
$$

$\Delta H_{0}^{\#}$ is the enthalpy of activation when $\Delta H^{\#}=0$ and usually has no physical significance and $\beta$ is the isokinetic temperature. A plot of $\Delta H^{\#}$ against $\Delta S^{\#}$ gave straight line with a good correlation coefficient $(r=0.971)$ for PCC (Fig. 4). The linear correlation between $\Delta H^{\#}$ and $\Delta S^{\#}$ indicates that all the substituted cis a-phenyl cinnamic acids follow common mechanism. The plot of log $\mathrm{k}_{\mathrm{obs}} 308 \mathrm{~K}$ versus log $\mathrm{k}_{\mathrm{obs}} 318 \mathrm{~K}$ gave a straight line with $(\mathrm{r}=0.987)$ (Fig. 5) good correlation coefficient for PCC. It indicates that all substituted compounds follow a common mechanism.

On applying Hammett equation with the usual substituent constant $\sigma$ and $\mathrm{kobs}_{\text {data }}$ of meta-and para- substituted cis- $\alpha$-phenyl cinnamic acids, a ' $V$ ' shaped curve is obtained (Fig.6). The electron-releasing substituents fall on one side 
of the curve with a negative slope and electron-withdrawing substituents on other side with a positive slope. This type of 'V' shaped curve in Hammett plot is reported earlier ${ }^{23-25}$.

The break in the Hammett plot may be due to the following three factors. (i) A change in the mechanism when one passes from electron donors to electron attractors (ii) A change in the rate determining step with change in the nature of substituent and (iii) $A$ change in the nature of the transition state.

The break in the Hammett plot is not due to the change in the rate determining step. The isokinetic plot and Exner plot reveals that there is no change in reaction mechanism. Hence, the break is mainly due to the change in the transition state.

Both electron-releasing and electron-withdrawing substituents facilitate the rate of the reaction considerably. The electron attractors accelerate the reaction only when the rate determining step proceeds with development of negative charge on the $\alpha$ or $\beta$-carbon in the cis- $\alpha$-phenylcinnamic acids.

Since the electron-releasing substituents also accelerate the rate of reaction, the transition state may be a carbonium ion

Table 1 Rate constants for the oxidation of cis-a-Phenyl cinnamic acids by PCC

\begin{tabular}{|c|c|c|c|}
\hline$[\mathbf{S}] \mathbf{~} \mathbf{1 0}^{\mathbf{2}} \mathbf{M}$ & {$[\mathbf{O X}] \mathbf{\times} \mathbf{1 0}^{\mathbf{4}} \mathbf{M}$} & {$\left[\mathbf{H}^{+}\right] \mathbf{~} \mathbf{1 0}^{\mathbf{1}} \mathbf{~}$} & $\mathbf{k}_{\mathbf{1}} \mathbf{\times} \mathbf{1 0}^{\mathbf{5}} \mathbf{s}^{-1}$ \\
\hline 1.0 & 5.0 & 2.0 & 7.00 \\
1.5 & 5.0 & 2.0 & 9.98 \\
2.0 & 5.0 & 2.0 & 12.68 \\
3.0 & 5.0 & 2.0 & 17.98 \\
\hline 1.5 & 2.50 & 2.0 & 10.21 \\
1.5 & 5.00 & 2.0 & 9.98 \\
1.5 & 7.50 & 2.0 & 9.80 \\
1.5 & 10.00 & 2.0 & 10.01 \\
\hline 1.5 & 5.0 & 1.0 & 6.79 \\
1.5 & 5.0 & 2.0 & 9.98 \\
1.5 & 5.0 & 3.0 & 12.20 \\
1.5 & 5.0 & 4.0 & 14.45 \\
\hline
\end{tabular}

$\%$ AcOH: $\mathrm{H}_{2} \mathrm{O}=50: 50(\mathrm{v} / \mathrm{v})$

Table. 2 Effect of $\left[\mathrm{NaClO}_{4}\right]$, [ $\left.\mathrm{MnSO}_{4}\right]$ and percentage of solvent on the reaction rate at $308 \mathrm{~K}$.

\begin{tabular}{|c|c|c|c|}
\hline$\left[\mathrm{NaClO}_{4}\right] \times 10 \mathrm{M}$ & {$\left[\mathrm{MnSO}_{4}\right] \times 10 \mathrm{M}$} & $\%$ of Solvent & $k_{1} \times 10^{5} \mathrm{~s}^{-1}$ \\
\hline 0.0 & - & - & 9.98 \\
\hline 1.0 & & - & 10.05 \\
\hline 2.0 & & - & 10.10 \\
\hline 3.0 & - & - & 10.12 \\
\hline- & 0.00 & - & 9.98 \\
\hline- & 1.00 & - & 5.97 \\
\hline - & 2.00 & - & 5.29 \\
\hline - & 3.00 & - & 4.92 \\
\hline \multirow[t]{4}{*}{-} & \multirow{4}{*}{ - } & $40-60$ & 8.75 \\
\hline & & $50-50$ & 9.98 \\
\hline & & $60-40$ & 10.51 \\
\hline & & ח ח ח & 1125 \\
\hline
\end{tabular}
$[S]=1.5 \times 10^{-2} \mathrm{M}$;
$[\mathrm{O}]=5.0 \times 10^{-4} \mathrm{M}$
$\left[\mathrm{H}^{+}\right]=2.0 \times 10^{-1} \mathrm{M}$ 
ISSN $2321-807 x$

Volume $12 \mathrm{Number} 5$

Journal of Advinses in Chemsitry

Table 3 Temperature effect and Thermodynamic parameters for the oxidation of cis- $\alpha$-Phenyl cinnamic acids by Pyridinium chlorochromate

\begin{tabular}{|c|c|c|c|c|c|c|c|}
\hline \multirow{2}{*}{ S.No. } & \multirow{2}{*}{ Substrate } & \multicolumn{4}{|c|}{$k_{1} \times 10^{5} s^{-1}$} & \multirow{2}{*}{$\begin{array}{c}\Delta \mathrm{H}^{\#} \\
\left(k J m o \Gamma^{1}\right)\end{array}$} & \multirow{2}{*}{$\begin{array}{c}-\Delta \mathrm{S}^{\#} \\
\left(J K^{1} \mathrm{~mol}^{1}\right)\end{array}$} \\
\hline & & $303 \mathrm{~K}$ & $308 \mathrm{~K}$ & $313 \mathrm{~K}$ & $318 \mathrm{~K}$ & & \\
\hline 1 & $-H$ & 6.70 & 9.98 & 14.70 & 22.15 & 61.13 & 123.40 \\
\hline 2 & $p-\mathrm{OCH}_{3}$ & 15.51 & 25.06 & 37.95 & 55.06 & 65.06 & 103.22 \\
\hline 3 & $p-\mathrm{OH}$ & 35.89 & 53.60 & 73.85 & 100.20 & 51.99 & 139.39 \\
\hline 4 & $p-\mathrm{NMe}_{2}$ & 51.30 & 75.80 & 115.10 & 160.40 & 58.98 & 113.50 \\
\hline 5 & $p-\mathrm{Cl}$ & 18.70 & 29.40 & 41.95 & 61.19 & 60.17 & 117.83 \\
\hline 6 & $p-\mathrm{NO}_{2}$ & 55.20 & 72.50 & 94.00 & 115.10 & 36.96 & 185.49 \\
\hline 7 & $m-\mathrm{NO}_{2}$ & 51.88 & 55.20 & 98.50 & 132.07 & 51.53 & 138.86 \\
\hline 8 & $m-\mathrm{OCH}_{3}$ & 7.10 & 10.50 & 14.00 & 19.00 & 49.42 & 161.33 \\
\hline
\end{tabular}

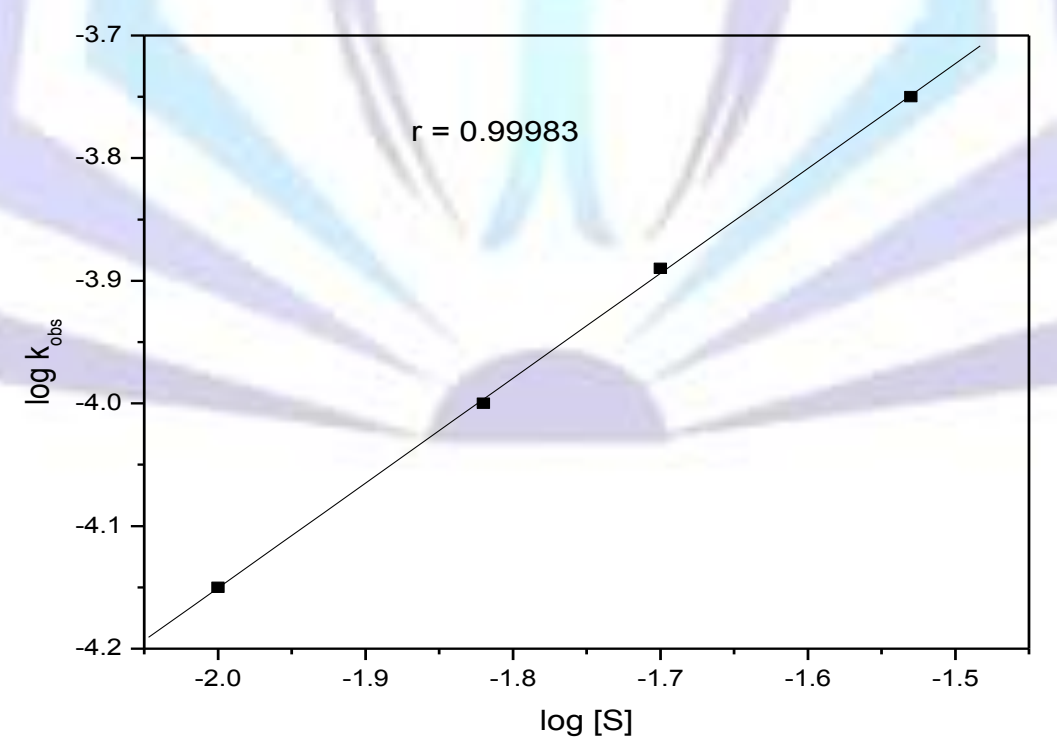

Fig. 1. Plot of log $k$ versus $\log [\mathrm{PCA}]$ 


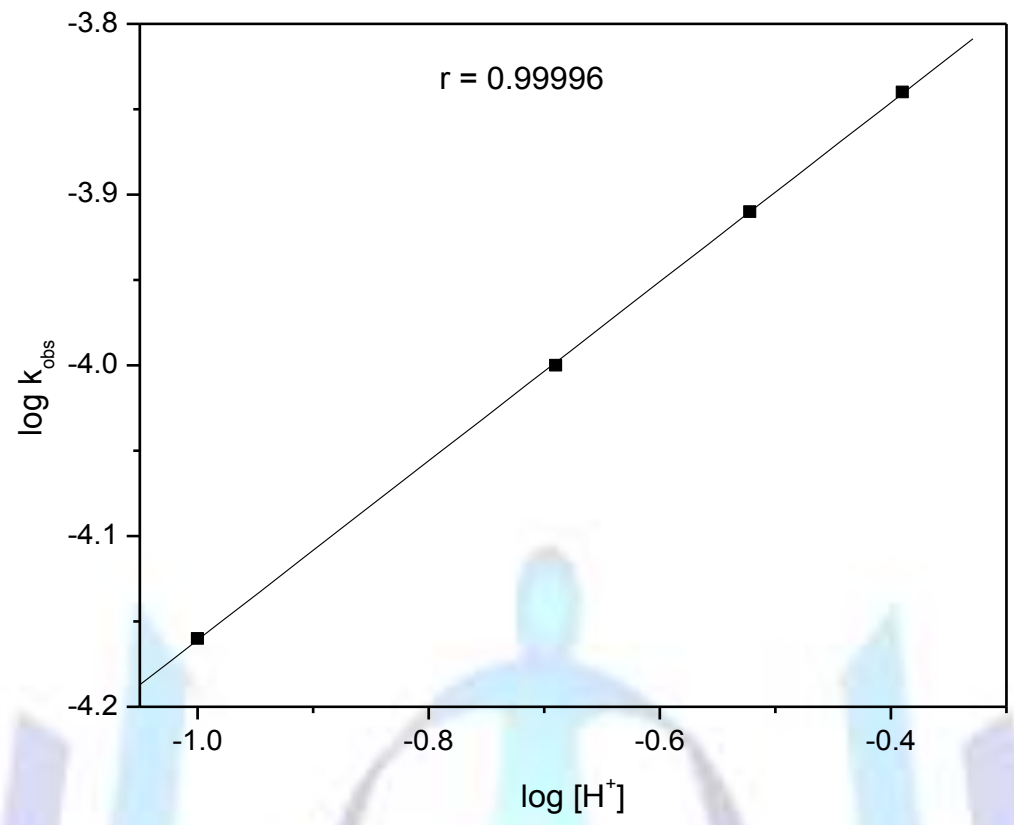

Fig. 2. Plot of log k versus $\log \left[\mathrm{H}^{+}\right]$

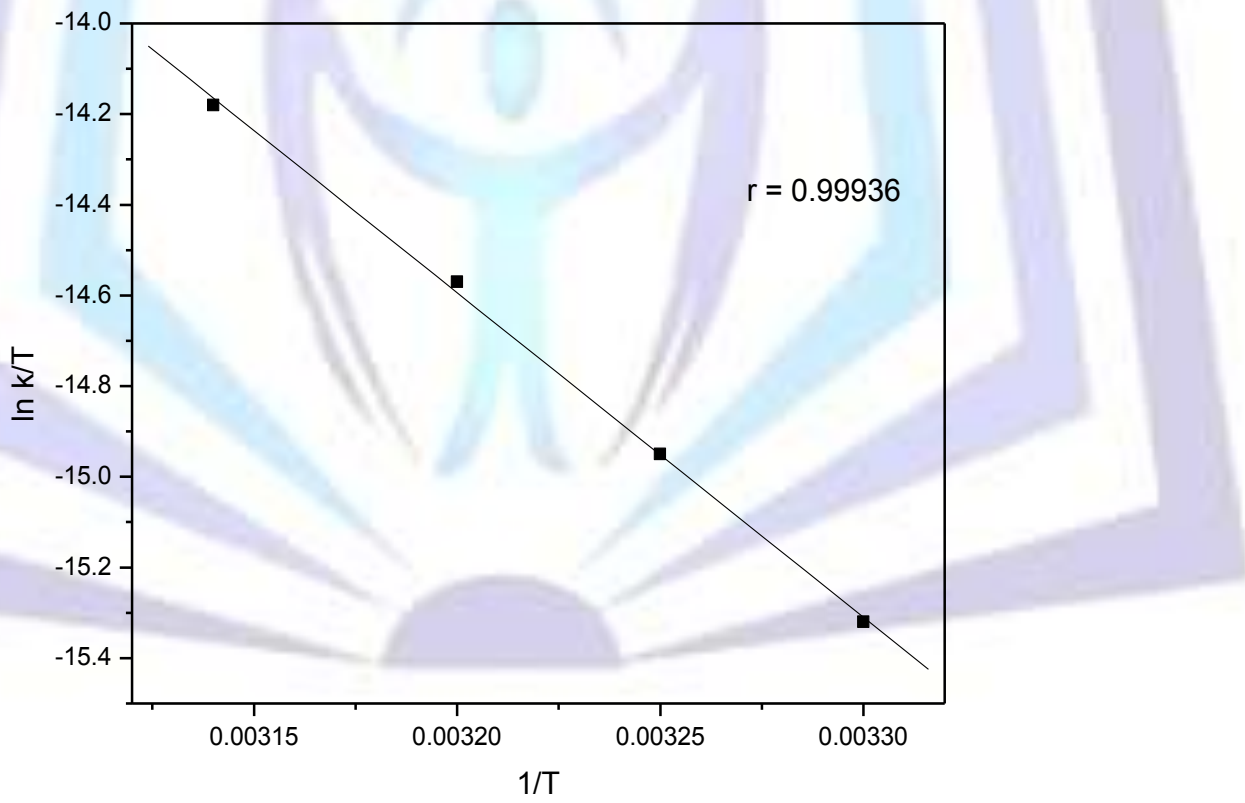

Fig. 3. Plot of $\log k / T$ versus $1 / \mathrm{T}$ 


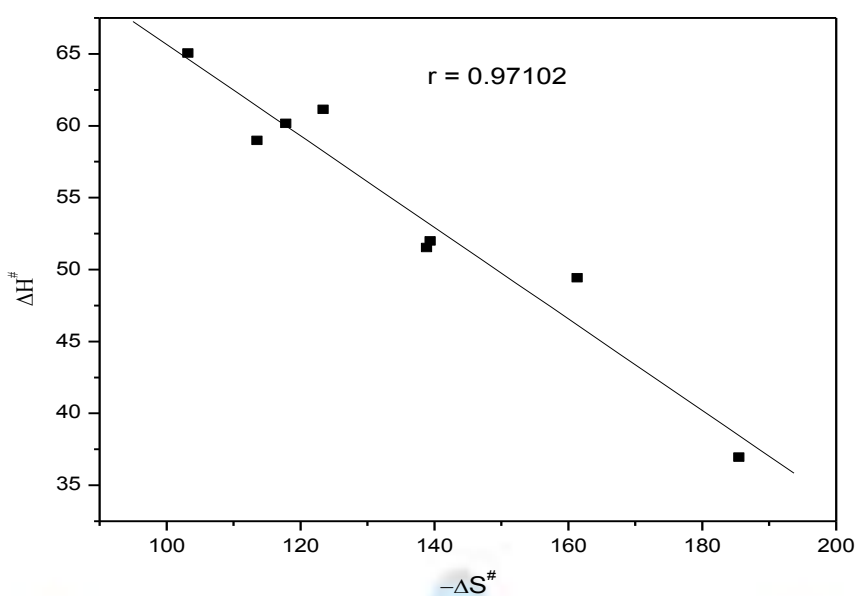

Fig. 4. Plot of $\Delta H^{\#}$ versus $-\Delta \mathrm{S}^{\#}$

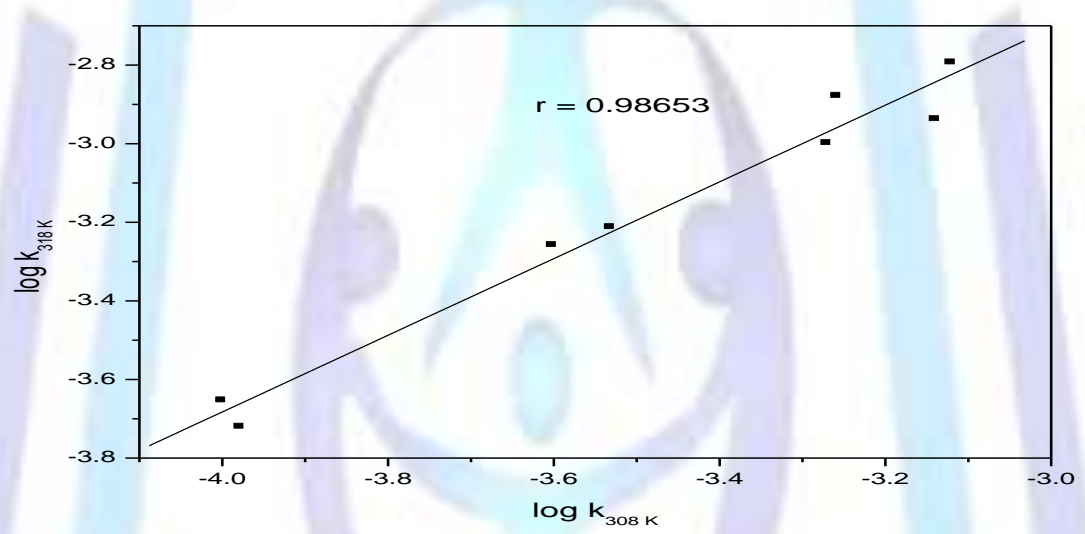

Fig. 5. Plot of $\log k_{318} \mathrm{~K}$ versus $\log k_{308} \mathrm{~K}$

\section{Hammett plot}

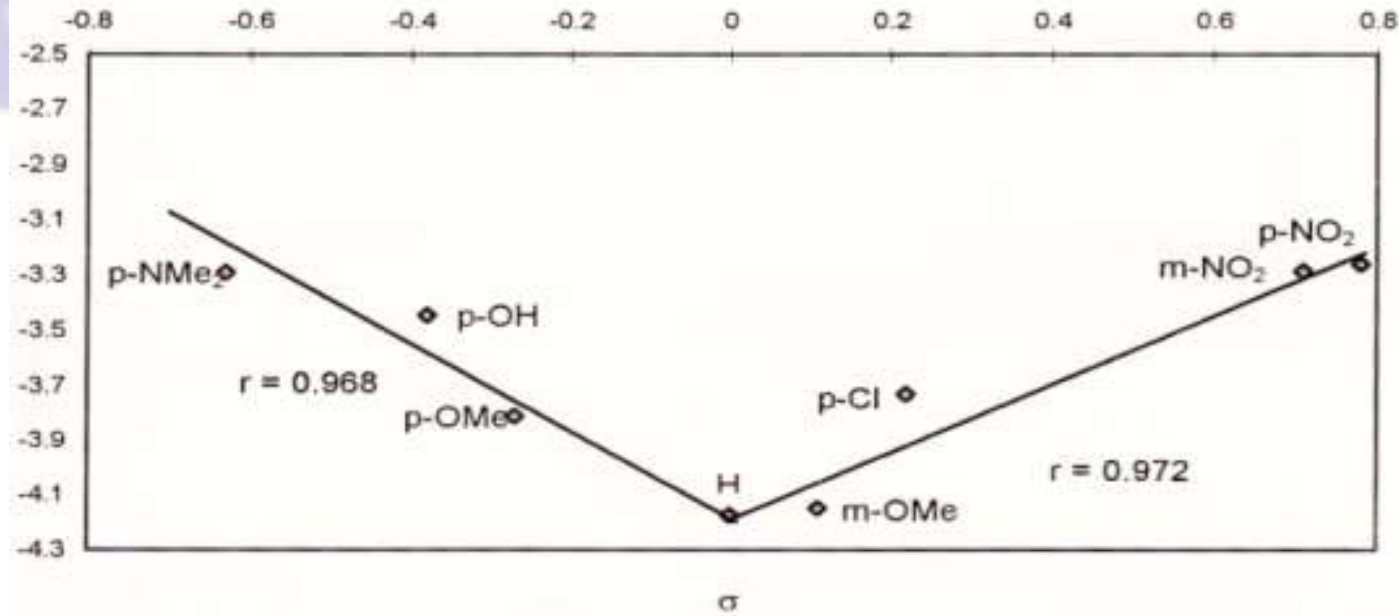

Fig. 6. Plot of log $\mathrm{k}_{\mathrm{obs}}(303 \mathrm{~K})$ Versus $\sigma$ 


\section{References}

1. G. Cainelli and G. Cardillo, "Chromium Oxidations in Organic Chemistry", Springer Verlag, Berlin, 1984.

2. P. Aparna, S. Kothari and K.K. Banerji, Proc. Ind. Acad. Sci., 1995, 107, 213.

3. D. Doyamoy and M.K. Mahendra, J. Org. Chem., 1990, 55, 5848.

4. R. Gurumurthy and K. Karunakaran, J. Indian Chem. Soc., 1996, 72, 349.

5. G. Mangalam and SP. Meenakshisundaram, J. Indian Chem. Soc., 1991, 68, 77.

6. R. Asopa, A. Mathur and K.K. Banerji, J. Chem. Res. (S), 1992, 152.

7. E.J. Corey and G.W.J. Fleet, Tetrahedron lett., 1973, 4499.

8. J.R. Holum, J. Org. Chem., 1961, 26, 4814.

9. A. Bowers, T.G. Hatshall, E.R.H. Jones and A.J. Lemin, J. Chem. Soc., 1953, 2555.

10. J.C. Collins, W.W. Hess and F.J. Frank, Tetrahedron Lett., 1968, 3363.

11. H.H. Sisler, W.C.L. Ming, E. Metter and F.R. Hurley, J. Am. Chem. Soc., 1953, 75, 446.

12. F.S. Guziee and F.A. Luzzio, Synth., 1980, 691.

13. J.C. Collins and W.W. Hess, Org. Synth.,1972, 52, 5.

14. E.J. Corey and G. Schimidt, Tetrahedron Lett., 1975, 2647.

15. G.I. Poos, G.E. Anoth, R.E. Beyber and L.H. Sarett, J. Am. Chem. Soc., 1953, 75, 425.

16. E.J. Corey and J.W. Suggs, Tetrahedron Lett., 1975, 2647.

17. E.J. Corey and D.L. Boger, Tetrahedron Lett., 1978, 2461.

18. W.G.Dauben and D.M.Michino, J.Org.Chem., 1972, 42, 682.

19. G. Piancatalli, A. Scettri and M.D. Auria, Tetrahedron Lett.,1977,2199.

20. K.K. Banerji, J. Chem. Soc., Perkin II,1978,639.

21. Vogel's Textbook of Organic chemistry, Revised by Brian S.Furniss, Antony J.Hannaford, Peter W.G.Smith,and Austin R. Tatchell V ${ }^{\text {th }}$ ed., 1989.

22. K.B. Wiberg, "Oxidation in Organic Chemistry", (Academic Press, New York), 1967, 42.

23. P. Beltrame, C. Vegilo and M. Simonetta, Chem. Commun., 1966, 433.

24. R. Fuchs and D.H. Carlton, J. Org. Chem., 1962, 27, 1520.

25. G. Gardnerswain and W.P. Langsdorf, Jr., J. Am. Chem. Soc., 1951, 73, 2813

\section{Author' biography with Photo}

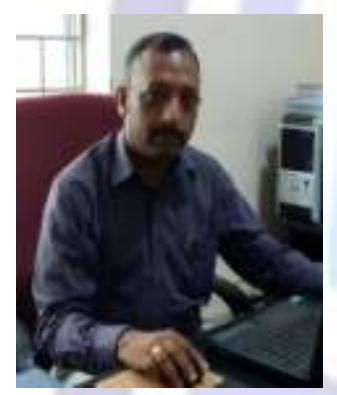

Dr.R.UDHAYAKUMAR, M.Sc,M.Ed,M.Phil, Ph.D Assistant Professor

Department of Chemistry

Room No: B -112

Anna University, BIT Campus

Tiruchirappalli 620024.

Contact No. : +919443441023

E mail : annauniversitychemistry@gmail.com : udhaya0123@gmail.com 